\title{
The Effect of Rigging Angle on Longitudinal Direction Motion of Parafoil-Type Vehicle: Basic Stability Analysis and Wind Tunnel Test
}

\author{
Takahiro Moriyoshi $\mathbb{D}^{1},{ }^{1}$ Kazuhiko Yamada, ${ }^{2}$ and Hiroyuki Nishida ${ }^{3}$ \\ ${ }^{1}$ Department of Mechanical Systems Engineering, Tokyo University of Agriculture and Technology, 2-24-16 Naka-cho, Koganei-shi, \\ Tokyo, Japan \\ ${ }^{2}$ Institute of Space and Astronautical Science, Japan Aerospace Exploration Agency, 3-1-1 Yoshinodai, Chuo-ku, Sagamihara City, \\ Kanagawa, Japan \\ ${ }^{3}$ Institute of Engineering, Tokyo University of Agriculture and Technology, 2-24-16 Naka-cho, Koganei-shi, Tokyo, Japan
}

Correspondence should be addressed to Takahiro Moriyoshi; s176462w@st.go.tuat.ac.jp

Received 27 April 2020; Revised 3 November 2020; Accepted 10 November 2020; Published 7 December 2020

Academic Editor: Jose Carlos Páscoa

Copyright (C) 2020 Takahiro Moriyoshi et al. This is an open access article distributed under the Creative Commons Attribution License, which permits unrestricted use, distribution, and reproduction in any medium, provided the original work is properly cited.

\begin{abstract}
The paraglider, a flexible flying vehicle, consists of a parafoil with flexible wings, suspension lines, and a suspended payload. At this time, the suspension lines have several parameters to be designed. Above all, a parameter called Rigging Angle (RA) is sensitive to the aerodynamic characteristics of a paraglider during flight. In this study, the effect of RA is clarified using the two-dimensional stability analysis and a wind tunnel test. The mechanisms about the parafoil-type vehicle stability are clarified through the experimental and analytical approaches as follows. The RA has an allowable range for a stable flight. When the RA is set out of the range, the parafoil cannot fly stably. Furthermore, the behavior of the parafoil wing in the case of lower RA than the allowable range is different from the case of higher RA. The parafoil collapses from the leading edge of the canopy and cannot glide in the case of lower RA.
\end{abstract}

\section{Introduction}

A parafoil-type vehicle is a flying vehicle using a parafoil, which is an inflatable airfoil, such as a paraglider. It has been developed for various purposes and is actually used in various fields, for example, sky sports, cargo transfer, and space transfer system. Especially, it has a significant advantage for space usage because of its good packing efficiency. Therefore, we propose the Martian Exploration Probe using a parafoiltype vehicle that is flying in the Martian atmosphere [1,2]. The packing efficiency of parafoil makes it possible to be stored in limited volume of a launch vehicle and an atmospheric-entry capsule. Therefore, the parafoil can generate the lift force enough for the flight in thin atmosphere like that of the Mars. However, no parafoil-type vehicle has experience of successful flight in such thin atmosphere. In a previous study, a drop test of a parafoil-type vehicle using a high-altitude balloon was carried out at approximately $30 \mathrm{~km}$ height in the Earth. In the experiment, although the parafoil of the vehicle was successfully deployed, it failed to conduct the gliding flight [3]. For achievement of successful flight in thin atmosphere, it is needed to understand the aerodynamic characteristics and the flight mechanism of the parafoil-type vehicle in more detail.

The aerodynamic design of the parafoil-type vehicle is not straightforward. The aerodynamic performance of the parafoil-type vehicle is governed by many parameters; airfoil profile, wing planform, suspension line length, rigging angle, and so on $[4,5]$. Here, the rigging angle (RA) is a parameter related to the attached angle of the parafoil suspended by 
different-length lines. The basic aerodynamic performance of the parafoil itself depends on the airfoil profile and the wing planform and can be investigated using wind tunnel tests or CFD (Computational Fluid Dynamics) simulations. On the other hand, the effects of design parameters related to the suspension lines are more complicated, because they affect not only drag increase with the number of the lines but also the trim angle of the vehicle. Especially, the RA should be carefully designed because it decides the performance of the gliding flight, because the RA is sensitive to flight stability of the parafoil-type vehicle. An inappropriate RA lead to crash of the parafoil-type vehicle. Our previous experiment showed when the designed RA was not appropriate, the parafoil-type vehicle could not glide and collapsed from the leading edge of the canopy. It is significant to overcome this problem for successful achievement of the Martian exploration. Understanding the effects of RA on the flight and attitude dynamics is indispensable.

There are several previous studies addressing the effects of RA. Stein et al. investigated the collapse behavior starting from the leading edge of the canopy, which was observed in the drop test of X-38 [6]. The collapse behavior was not predicted by prior theoretical analysis, and therefore, the towing experiment and motion-dynamics analysis with 8-degree of freedom was carried out [7]. In the towing experiment, it was shown that the RA should be set within an allowable range for the stable gliding flight, and the RA smaller than the appropriate values causes the collapse behavior starting from the leading edge of the canopy. In addition, the motion-dynamics analysis showed that the collapse behavior in the drop test was caused by decreasing of the trim angle of attack due to inappropriate RA and disturbances in the flight angle of attack due to the attitude motion which is called the alpha corridor. However, it was not shown why small RA causes the collapse behavior.

Ward et al. estimated the aerodynamic characteristics of a parafoil-type vehicle analysing the gliding angle and turning radius in the flight test. In the flight test, the RA and break angle were varied, and the changes in the aerodynamic characteristics were investigated [8]. The results showed the lift and drag coefficient can be made smaller by increasing RA, and it can change the gliding velocity. However, the attitude of the vehicle was not taken into account in their study, and the effects of the RA on the aerodynamic characteristics cannot be discussed correctly.

Willemsen et al. proposed an investigation method utilizing wind tunnel tests [9]. In their wind tunnel test, the RA was set by angle of line fixed to a table which is called as swivel table. The suspension lines were attached in distributed state on the swivel table. And then, aerodynamic characteristics were obtained changing the angle of the swivel table. As a result, the lift coefficient was smaller with pitch-up maneuver of the swivel table, which means decreasing of the RA. However, strict relationship of the RA and aerodynamic characteristics could not be discussed, because the angle of attack of the parafoil was not measured in the wind tunnel test.

As mentioned above, there are several previous studies investigating the effect of the RA on the aerodynamic charac-

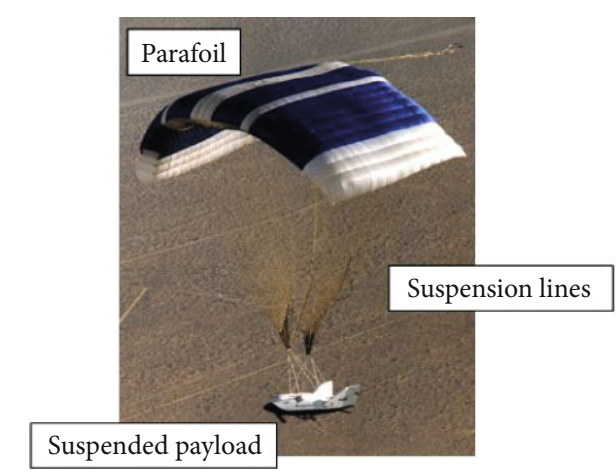

Figure 1: Typical parafoil at the X-38 mission [6].

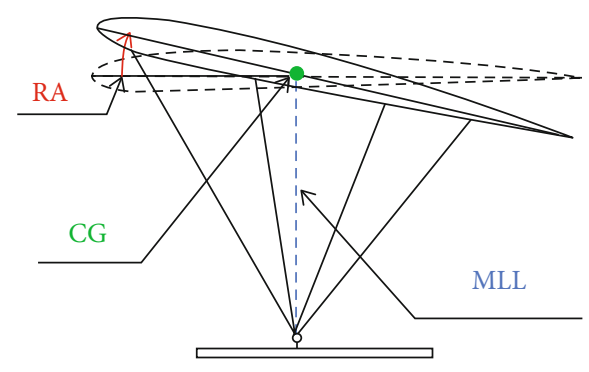

Figure 2: Two-dimensional model of parafoil.

teristics. These researches showed that control of the RA is effective for control of the gliding slope and gliding velocity, and the smaller RA than appropriate value causes the collapse behavior. It is predicted that the flight in the Mars atmosphere is difficult as in the stratosphere, and therefore, it is indispensable for the success of the mission to clarify why the stable gliding flight strongly depends on the RA setting. In this study, the attitude stability analysis and wind tunnel tests are conducted to clarify the mechanism of the collapse behavior at small RA and to indicate the range of the RA required for the stable flight. The analysis model adopted in this study is constructed assuming conditions of the wind tunnel experiments, in which the testing model of the parafoil wings is fixed to the bottom surface of the wind tunnel only by suspension lines, and flies and moves freely except this constraint of the suspension lines. In this wind tunnel test, a rigid parafoil model is used to eliminate the influence of the inflatable parafoil and clarify the characteristics of RA, which is a parameter of the suspension line.

\section{Modelling of Parafoil-Type Vehicle for Flight Stability Analysis}

A parafoil-type vehicle such as a paraglider is composed of three elements; an inflatable wing called as a parafoil, a suspended payload, and suspension lines are shown in Figure 1.

In this study, the configuration of a parafoil-type vehicle is simplified for the two-dimensional modelling as shown in Figure 2. The payload is assumed to be fixed to a point on the ground for simulating the wind tunnel experiment, in which the testing model of the parafoil is fixed to the bottom surface of the wind tunnel only by suspension lines, and flies and moves freely except this constraint of the suspension lines. 


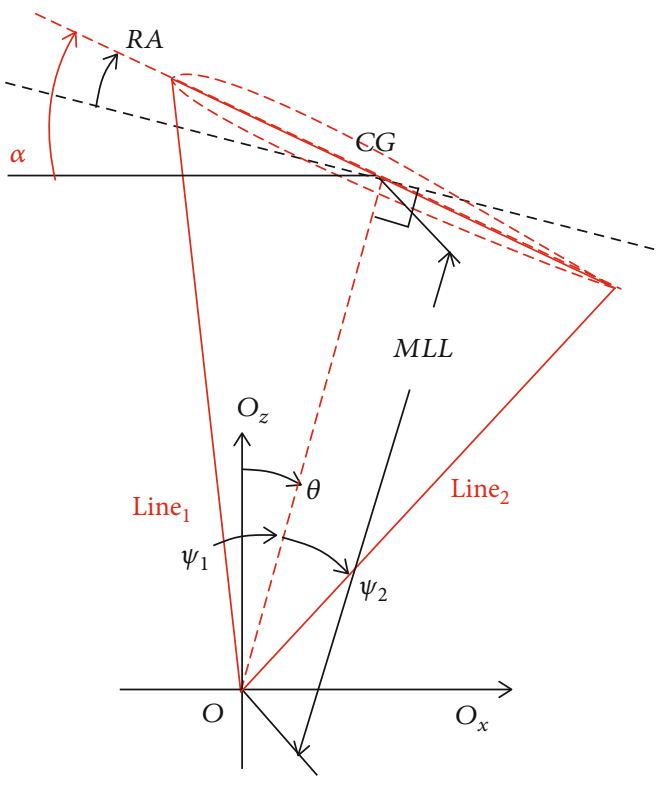

(a)

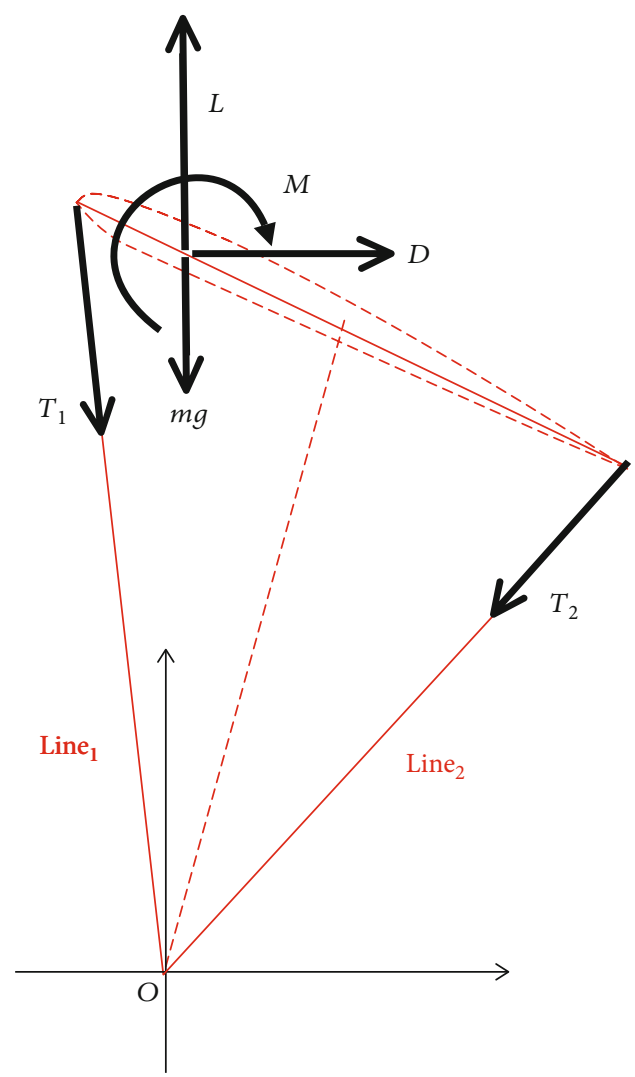

(b)

Figure 3: Schematic of the analytical model. (a) Definition of analysis parameters. (b) Definition of acting force and moment.

It can two-dimensionally rotate around the fixed point. In this model, the three-dimensional effect of the parafoil is not considered for simplicity. In addition, in order to investigate the effect of suspension lines parameters on attitude stability, the deformation of the parafoil, which is a flexible structure, is ignored and assumed to be rigid wings.

Many parameters including the airfoil (parafoil) profile have to be defined to design a parafoil-type vehicle. Especially, the Center of Gravity (CG), a Mean Line Length (MLL), and a Rigging Angle (RA) are parameters defining the relative positions of the parafoil to the payload and its attitude as shown in Figure 2. The CG is defined to be at the intersection of the vertical line from the payload with the chord of the parafoil at zero angle of attack. The MLL which is the typical suspension line length is the distance from the horizontal chord line of the parafoil to the payload. The RA is the angle between the parafoil chord and the horizontal line, and positive in the clockwise rotation.

\section{Attitude Stability Analysis Model}

The objective of this study is to investigate the relation between the collapse behavior and the RA and clarify its mechanism. Therefore, the flight stability analysis is conducted in the two-dimensional space and the one-degree of freedom model is adopted for simplicity [10]. In addition, the aerodynamic characteristics of the parafoil are theoretically estimated.

3.1. Assumptions. The definitions of the coordinate and aerodynamic forces are shown in Figure 3. The vertical axis of the model is the dashed line connecting CG and the payload (the origin $\mathrm{O}$ ). The angle of attitude $\theta$ of the analytical model is given as the angle between the vertical axis of the model and the $O_{z}$ axis as in Figure 3. The $\psi$ represents the angle between the suspension line and the vertical axis of the model and is calculated by design parameters such as MLL and chord length.

A positive direction of the force is right and upward direction. A positive direction of the moment is the clockwise rotation direction. The assumptions in the model are the following:

(i) The parafoil and suspension lines are rigid, but the suspension lines can support only tensile force

(ii) The parafoil two-dimensionally rotates around the payload (one-degree of freedom).

(iii) The pressure center is at $25 \%$ chord length from the leading edge

(iv) The parafoil wing is connected with two suspension lines at the leading and trailing edge 
(v) The center of gravity is at $50 \%$ chord length from the leading edge

3.2. Governing Equations. The equation of rotational motion around the suspended payload (the origin) is written as the following equation.

$$
\begin{aligned}
& N(\alpha, \theta)(\mathrm{CG}-x) c \cos \mathrm{RA}+A(\alpha, \theta)(\mathrm{MLL}+(\mathrm{CG}-x) c \sin \mathrm{RA}) \\
& \quad+M(\alpha)=m \mathrm{MLL}^{2} \frac{d^{2} \theta}{d t^{2}} .
\end{aligned}
$$

$N$ and $A$ is the parallel and vertical force against the model, respectively, and is expressed as follows.

$$
\begin{aligned}
& N=(L-m g) \cos \theta+D \sin \theta, \\
& A=-(L-m g) \sin \theta+D \cos \theta .
\end{aligned}
$$

The following relationship holds among $\alpha, \theta$, and $R A$.

$$
\mathrm{RA}=\alpha-\theta
$$

When the vehicle is in the trim condition, the right-hand side of Eq. (1) becomes zero, and the following equations (4) and (5) can be derived from the above equations, which are called the equation of attitude balance.

$$
\begin{aligned}
\sin (\theta-\gamma)= & \frac{(\mathrm{CG}-x) c}{r} \frac{(L-m g) \cos \alpha+D \sin \alpha}{\sqrt{(L-m g)^{2}+D^{2}}} \\
& +\frac{M}{r \sqrt{(L-m g)^{2}+D^{2}}}, \\
\tan \gamma= & \frac{D}{(L-m g)} .
\end{aligned}
$$

From Eqs. (4) and (5), the angle of attitude and the angle of attack in the balance condition can be obtained by giving the aerodynamic characteristics of the parafoil and the uniform flow condition.

3.3. Aerodynamic Characteristics of the Parafoil [4, 11]. The solution of the equation of the attitude balance strongly depends on the aerodynamic characteristics of the parafoil. Therefore, it is important to provide an appropriate aerodynamic model for reliable analysis. In this study, the aerodynamics characteristics of the parafoil are expressed as a function of the angle of attack as shown in the following equations. For the case of conventional airfoil, it is well known that the model can provide good approximation of the aerodynamic characteristics for angle of attack range smaller than the stall angle. Note that the lift coefficient of the parafoil reduces due to the curvature of the arch shape comparing to conventional airfoil.

$$
C_{L}=C_{L, \alpha}\left(\alpha-\alpha_{0}^{*}\right)
$$

TABLE 1: Aerodynamic parameters.

\begin{tabular}{lc}
\hline$\alpha_{0} *$ & $-3.6[\mathrm{deg}]$ \\
$\alpha_{\lim }$ & $13[\mathrm{deg}]$ \\
$C^{\alpha}{ }_{L, \alpha}$ & $0.109[1 / \mathrm{deg}]\left(\mathrm{Re}: 2 \times 10^{5}\right)$ \\
$C_{L, \alpha}$ & $0.0609[1 / \mathrm{deg}]$ \\
$C^{\prime \prime}{ }_{L, \alpha}$ & $0.0618[1 / \mathrm{deg}]$ \\
$C_{L 2, \alpha}$ & $-0.025[1 / \mathrm{deg}]$ \\
$C_{D \min }$ & 0.0185 (include line drag) \\
$e$ & 0.9 \\
$A R$ & 3.0 \\
$C_{M}$ & -0.08 \\
$\tau$ & 0.095 \\
\hline
\end{tabular}

TABLE 2: Design parameters and mainstream conditions.

\begin{tabular}{lcc}
\hline & Chord length $c[\mathrm{~m}]$ & 0.30 \\
& Wing area $S\left[\mathrm{~m}^{2}\right]$ & 0.90 \\
Design parameter & Aerodynamic center ac [\%] & 25 \\
& CG [\%] & 45 \\
MLL $[\mathrm{m}]$ & 0.62 \\
Airflow condition & Mass $m[\mathrm{~kg}]$ & 0.2 \\
\hline
\end{tabular}

$$
\begin{aligned}
& C_{D}=C_{D \text { min }}+K C_{L}{ }^{2}, \\
& C_{M}=\text { const. }
\end{aligned}
$$

The coefficient $K$ is expressed as follows:

$$
K=\frac{1}{\pi e \mathrm{AR}} .
$$

When the angle of attack is larger than the stall angle, the aerodynamics model becomes more complicated. The aerodynamic characteristics in the stall condition are given by the following equations.

$$
\begin{aligned}
C_{L} & =C_{L, \alpha}\left(\alpha_{\lim }-\alpha_{0}{ }^{*}\right)+C_{L 2, \alpha}\left(\alpha-\alpha_{0}{ }^{*}\right), \\
C_{D} & =C_{D \min }+K\left[C_{L, \alpha}\left(\alpha-\alpha_{0}{ }^{*}\right)\right]^{2}, \\
C_{M} & =\text { const. }
\end{aligned}
$$

In this study, clarkY airfoil is applied for analysis because this airfoil is used in conventional parafoil $[4,12]$. The lift curve slope and the minimum parasite drag coefficient of the airfoil are determined referring to Xfoil data [13]. The aspect ratio of the parafoil is not so high, and so the threedimensional effects of the airfoil must be considered; the lift curve slope is corrected by multiplying a factor $k$ as shown in Eqs. (10) and (11). Here, $\tau$ changes depending on the aspect ratio and is set to be 0.095 according to Ref. [4]. A Line drag was given to analysis converting into parafoil drag as minimum parasite drag coefficient $C_{D \text { min }}$. Pitching moment coefficient of airfoil is given as a constant value. The 


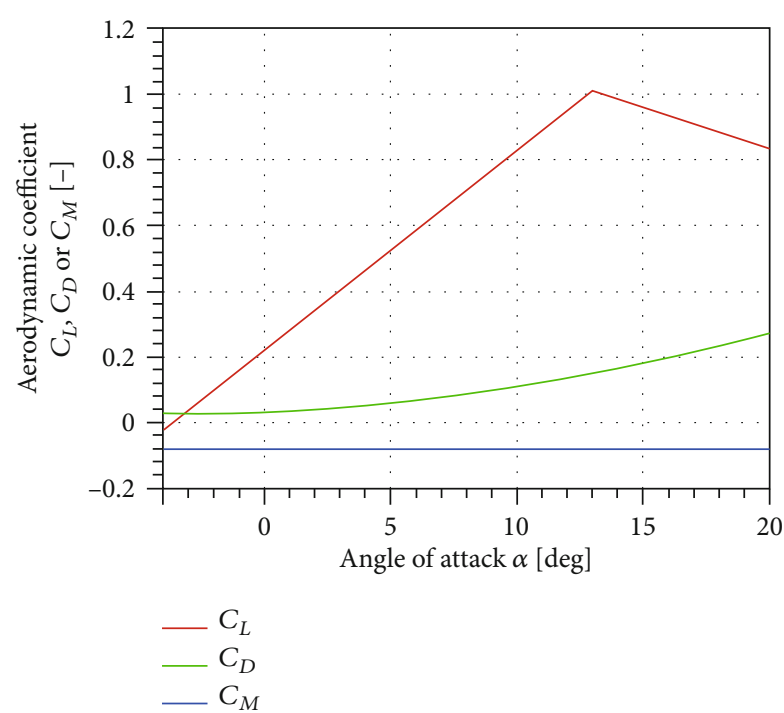

Figure 4: Aerodynamic characteristics of the parafoil.

parameters and conditions used for the analysis are summarized in Tables 1 and 2. Figure 4 shows the aerodynamic characteristics of the parafoil.

$$
\begin{aligned}
C_{L \alpha}^{\alpha{ }^{\prime}} & =k \mathrm{C}_{L \alpha}^{\alpha}, \\
k & =\frac{2 \pi \mathrm{AR}}{C_{L \alpha}^{\alpha}} \tanh \left(\frac{C_{L \alpha}^{\alpha}}{2 \pi \mathrm{AR}}\right), \\
C_{L \alpha} & =\frac{\pi C_{L \alpha}^{\alpha{ }^{\prime}} \mathrm{AR}}{\pi \mathrm{AR}+C_{L \alpha}^{\alpha{ }^{\prime}}(1+\tau)}\left[\mathrm{rad}^{-1}\right] \\
& =\frac{\pi^{2} C_{L \alpha}^{\alpha}{ }^{\prime} \mathrm{AR}}{180\left(\pi \mathrm{AR}+C_{L \alpha}^{\alpha}{ }^{\prime}(1+\tau)\right)}\left[\mathrm{deg}^{-1}\right] .
\end{aligned}
$$

3.4. Necessary Conditions for Stable Flight. The balance angle of attitude obtained in the attitude balance equation is only one of the necessary conditions for the stable gliding flight. Following other conditions have to be satisfied.

(i) The derivative of the pitching moment is negative at the trim angle of attack (a condition for the static stability)

(ii) Tension of all risers is positive

When the conditions (i) and (ii) are satisfied at the balance angle of attitude, the parafoil-type vehicle accomplishes the stable gliding flight. Tension of the suspension line is written as the following equations that are derived from geometric relations.

$$
\mathrm{T}_{1}=\frac{\mathrm{CG} c}{\mathrm{MLLsin} \psi_{1}}\left(\frac{M}{c}+N(1-x) \cos \mathrm{RA}+A(1-x) \sin \mathrm{RA}\right),
$$

$$
T_{2}=\frac{(1-\mathrm{CG}) c}{\text { MLLsin } \psi_{2}}\left(-\frac{M}{c}+N x \cos \mathrm{RA}+A x \sin \mathrm{RA}\right) .
$$

3.5. Results of the Analysis. Figure 5 shows the pitching moment

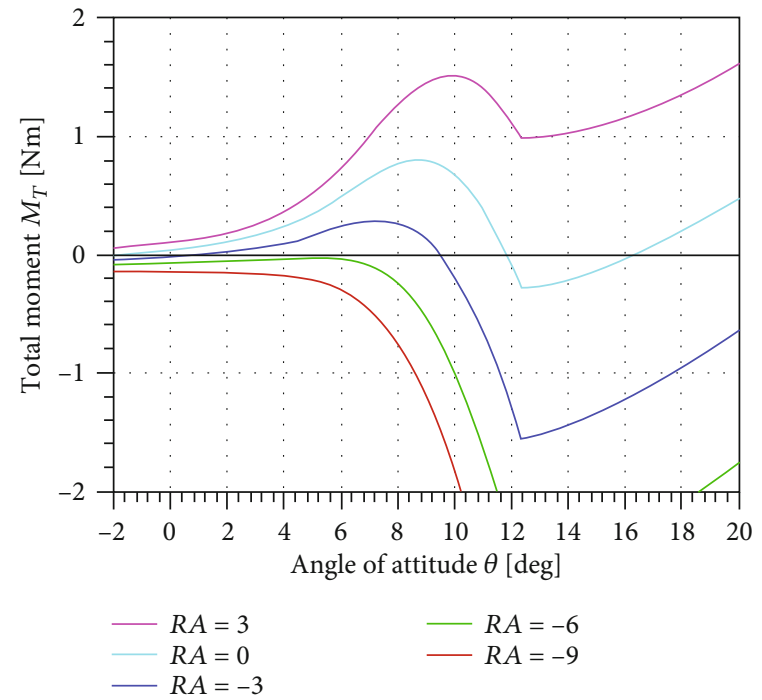

FIgURE 5: Pitching moment characteristics of the parafoil for various $R A$.

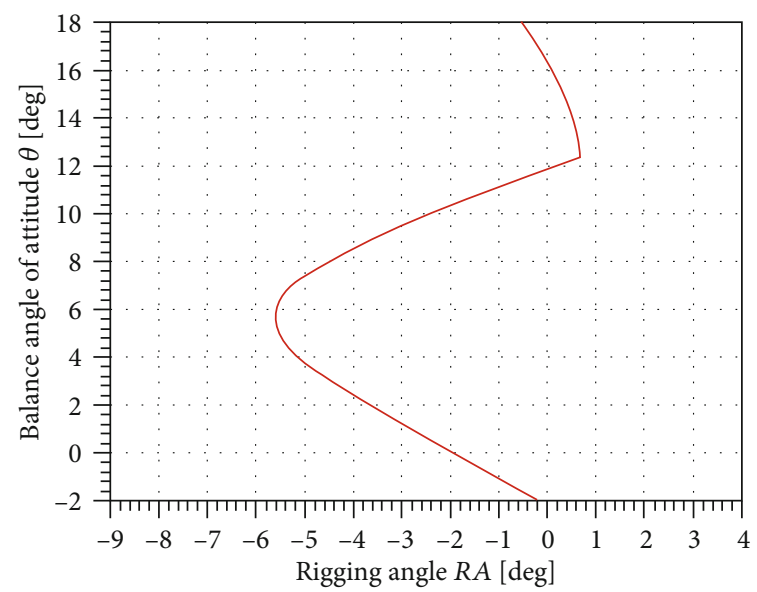

Figure 6: The relation between rigging angle and the angle of attitude in the balanced points.

(the left-hand side of Eq. (1)) characteristics around the origin for various RAs; the horizontal axis indicates the angle of attitude. As shown in the result, the pitching moment characteristics strongly depend on the RA; the attitude balance point, where the moment becomes zero, changes with the RA. Furthermore, there is no balance point in the case of smaller RA than -5.6 degrees. In these cases, the parafoil continuously makes pitch-down motion (rotates in the counter-clockwise direction), because the moment is always negative. On the other hand, the balance point does not exist also in larger RA than 0.7. And in this condition, the parafoil continuously makes pitch-up motion (rotates in the clockwise direction) because of positive pitching moment at all angles of attitude.

Figure 6 shows the relationship between the RA and the angle of attitude in the trim condition. As shown in the figure, when the RA is appropriately determined, several balance points in angle of attitude are obtained. The result indicates that the RA must be set in the range from 0.7 to -5.6 degrees 


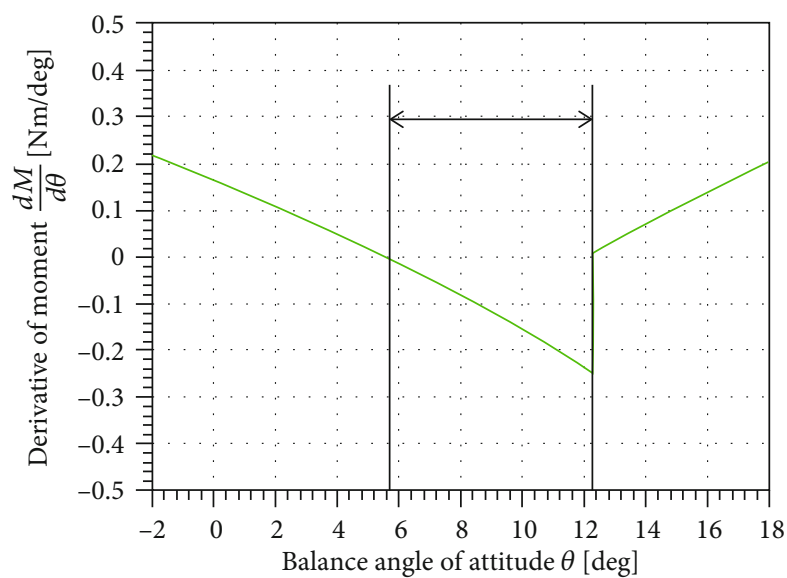

FIGURE 7: The derivative of the pitting moment as a function of the balance angle of attitude.

for making the balance angle of attitude. In addition, the attitude balance can be achieved at any angle of attitude by choosing appropriate RA. Note that it does not mean that the stable gliding flight can be accomplished only by the choosing the appropriate RA, because other necessary conditions must be satisfied at the same time.

Next, the condition for the static stability is discussed. Figure 7 shows the derivative of the pitching moment as a function of the balance angle of attitude. The negative derivative means that the static stability is achieved at that balance angle of attitude which can be achieved by choosing appropriate RA. The result indicates that the angle of attitude in the stable flight ranges from 5.8 to 12.2 degrees.

The flight attitude is uniquely determined by setting the RA within the appropriate range, and the flight angle of attitude increases with the RA.

Finally, the necessary condition (ii) for the stable flight is discussed; the tension of all suspension lines must be positive so as not to collapse. The tensions of suspension lines are plotted as a function of the balance angle of attitude in Figure 8. Angle of attitude larger than 3.7 degrees is required for positive tension. Therefore, the condition for positive tension is automatically satisfied when the condition for the static stability is satisfied. Moreover, an important insight about the collapse behavior can be obtained in the discussion of the line tension. Smaller RA tends to make the vehicle conduct the pitch-down motion as discussed in Figure 5, and reduction of the attitude angle eventually leads to negative tension of the line connecting to the leading edge. That means that the parafoil collapses to the front when the RA is smaller than the appropriate value.

The results of this analysis were summarized in Figure 9. The range where the static stability is achieved is shown by the solid line in Figure 9. The parafoil-type vehicle assumed in this study can fly stably, if the RA is set in the range from 0.7 to -5.6 degrees. And the angle of attitude of the parafoil in the stable flight depends on the RA and it varies in the range from 5.8 to 12.2 degrees depending on RA.

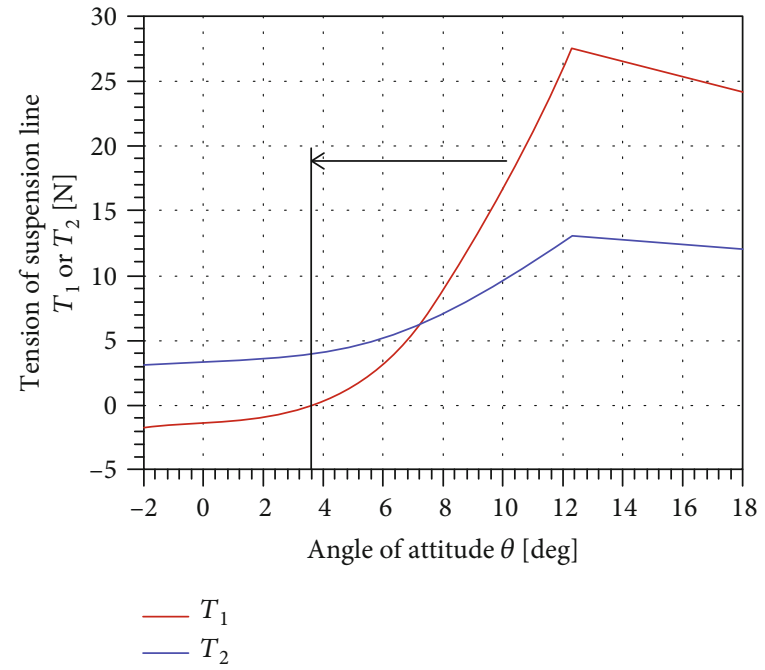

FIgURE 8: Tensions of suspension lines as a function of the attitude of angle.

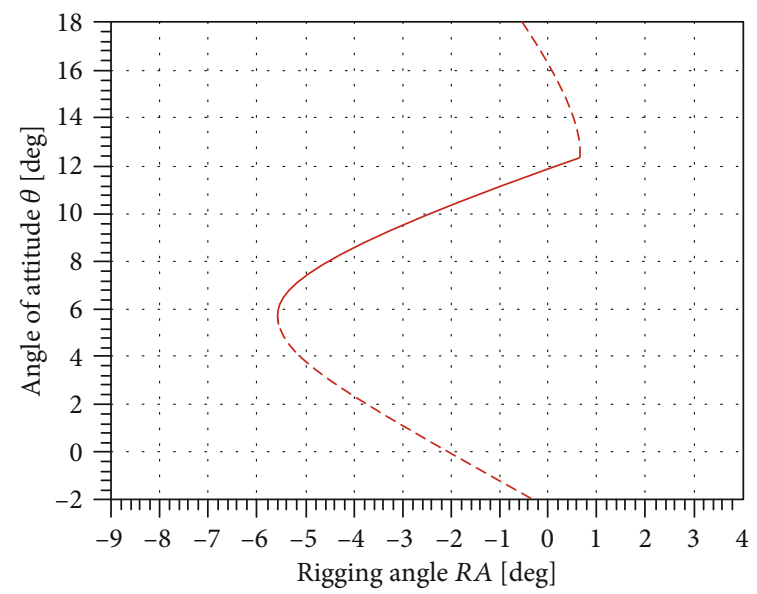

FIgURE 9: The relation between rigging angle and the angle of attitude in the stable flight points.

\section{Wind Tunnel Test}

The wind tunnel test was carried out for validation of attitude stability analysis. In this study, the low-speed wind tunnel in ISAS/JAXA is used. The diameter of the test section is $1.6 \mathrm{~m}$, and the test section is open to the air. The range of operable wind velocity is about from 10 to $50 \mathrm{~m} / \mathrm{s}$. The experimental model is a model that reproduces the motion in a twodimensional plane for clarifying attitude stability analysis. In this test, we obtain the effect of RA on the attitude stability of the parafoil by acquiring the behavior of the parafoil and the tendency of the angle of attack with respect to RA.

4.1. Test Model and Test Method. The test model that is semirigid model with a rigid parafoil and suspension lines was used. The Figures 10 and 11 show the schematic diagrams and photographs of the test model. The specifications of the model are shown in Table 3. The rigid parafoil was supported by two lines, and the length was adjusted to set the RA. The 

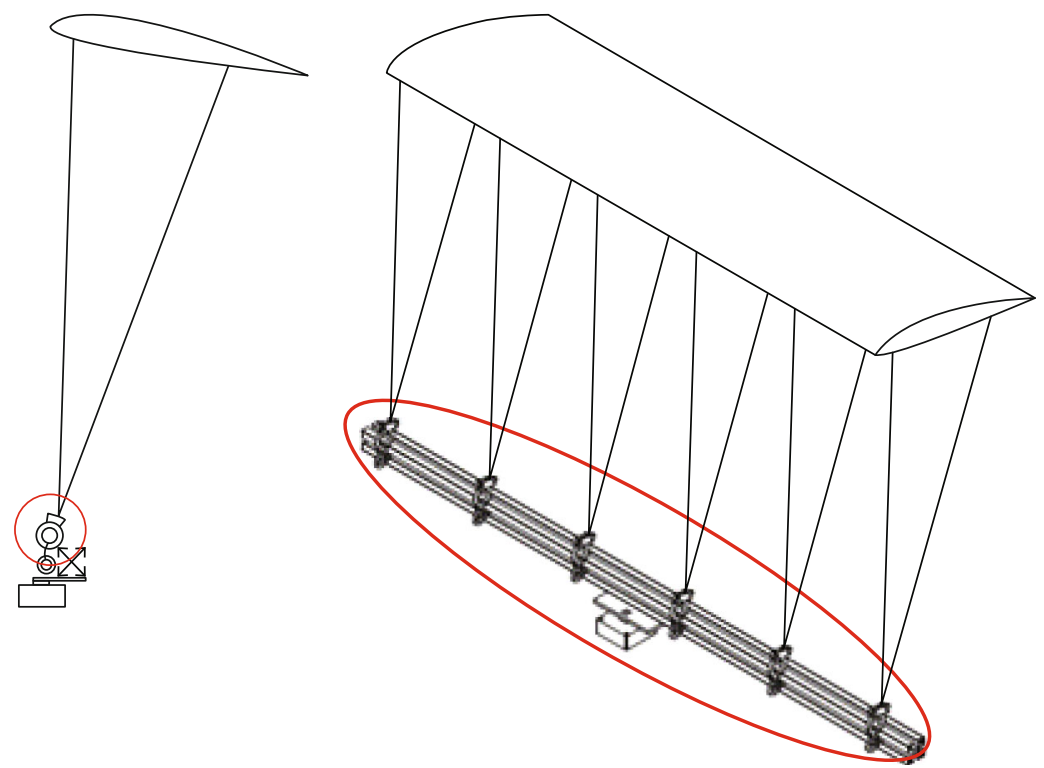

(a)

(b)

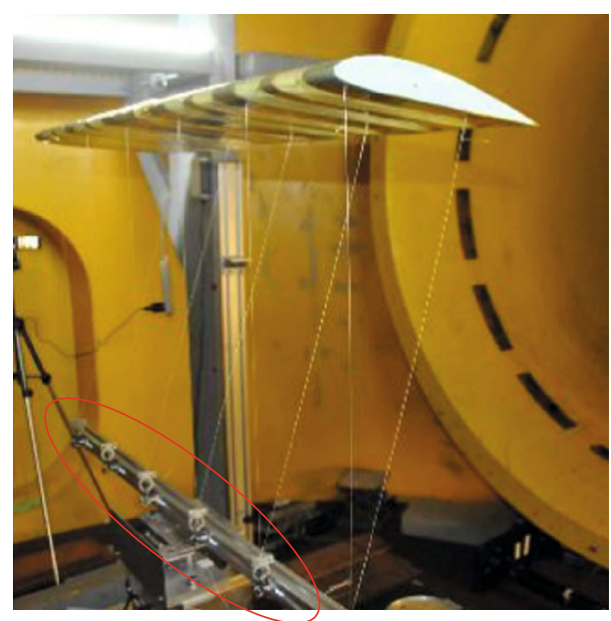

(c)

FIgURe 10: Pattern diagram and picture of the test model. (a) Side view. (b) Isometric view. (c) Actual picture of the test model.
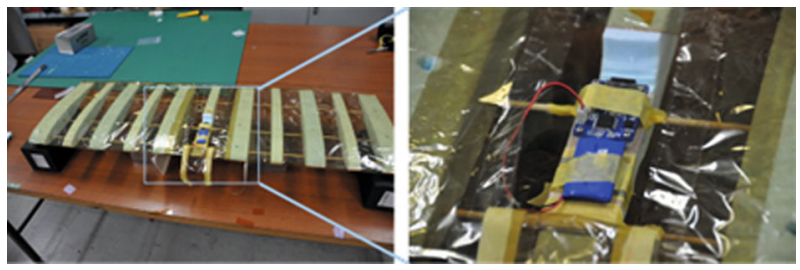

(a)

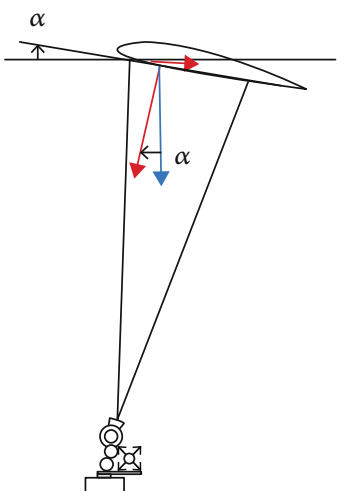

(b)

FIGURE 11: Installation position of a three-axis acceleration sensor-logger. (a) Appearance of the installation position of the sensor-logger. (b) Definition of acquired acceleration and gravitational acceleration used in the calculation of the angle of attack of test model. 
TABLE 3: Design parameter of test model and test condition of wind tunnel test.

\begin{tabular}{|c|c|c|c|}
\hline \multicolumn{4}{|c|}{ Design parameter of test model } \\
\hline Parafoil area $\left[\mathrm{m}^{2}\right]$ & 0.27 & MLL + (ring-shaped part + shackle $)[\mathrm{m}]$ & $0.54+0.080$ \\
\hline Chord length $[\mathrm{m}]$ & 0.3 & CG [\%] & $45 \%$ \\
\hline Aspect ratio [-] & 3 & Suspension line material & Vectran \\
\hline Mass of parafoil $[\mathrm{kg}]$ & 0.2 & Diameter of suspension lines $[\mathrm{mm}]$ & 0.47 \\
\hline Airfoil section & Clark Y & Number of suspension lines [-] & 12 \\
\hline \multicolumn{4}{|c|}{ Parameter of test condition } \\
\hline RA [deg] & 4 to -9 & Dynamic pressure $[\mathrm{Pa}]$ & $60,70,100,120,150$ \\
\hline
\end{tabular}

TABLE 4: Suspension line length to determine RA (MLL: $0.54 \mathrm{~mm}$, CG: $45 \%$ ).

\begin{tabular}{|c|c|c|c|c|c|}
\hline \multirow[b]{2}{*}{ RA [deg] } & \multicolumn{2}{|c|}{ Suspension line length [mm] } & \multirow[b]{2}{*}{ RA [deg] } & \multicolumn{2}{|c|}{ Suspension line length [mm] } \\
\hline & $\begin{array}{l}\text { Attached on } 10 \% \\
\text { chord length }\end{array}$ & $\begin{array}{l}\text { Attached on } 70 \% \\
\text { chord length }\end{array}$ & & $\begin{array}{l}\text { Attached on } 10 \% \\
\text { chord length }\end{array}$ & $\begin{array}{l}\text { Attached on } 70 \% \\
\text { chord length }\end{array}$ \\
\hline$\overline{4}$ & 548.7 & 536.5 & -3 & 536.0 & 545.6 \\
\hline 3 & 546.9 & 537.8 & -4 & 534.1 & 546.9 \\
\hline 2 & 545.1 & 539.1 & -5 & 532.3 & 548.2 \\
\hline 1 & 543.3 & 540.4 & -6 & 530.5 & 549.5 \\
\hline 0 & 541.5 & 541.7 & -7 & 528.6 & 550.8 \\
\hline-1 & 539.6 & 543.0 & -8 & 526.8 & 552.1 \\
\hline-2 & 537.8 & 544.3 & -9 & 524.9 & 553.3 \\
\hline
\end{tabular}

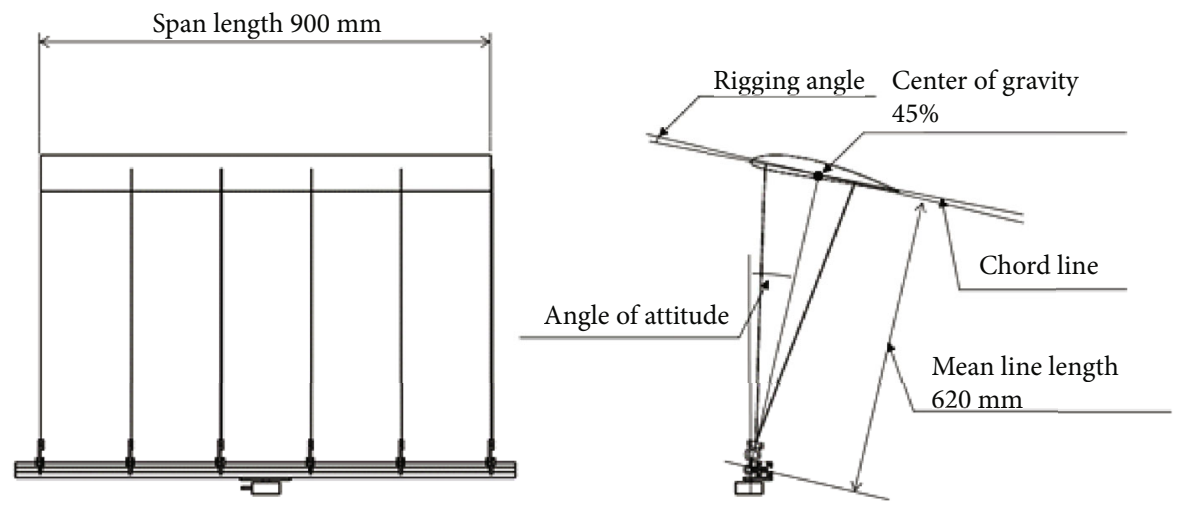

FIGURE 12: Details of the wind tunnel test model.

Table 4 shows the length of the front line and the rear line to make the RA be the test parameter. The detailed geometry of the wind tunnel test model is shown in Table 5 and Figure 12.

The suspension lines were fixed on the upper side of the ring shape parts indicated by red circle in Figure 10. When the lines are fixed, its length is adjusted precisely to set the RA. This part was mounted using a shackle so that it had a degree of freedom in the pitch direction. The motion in the two-dimensional plane was reproduced by distributing and fixing these parts in the span direction. As a result, it is possible to simulate slack of the suspension lines and the movement of the parafoil, while the deformation of the parafoil was ignored. The test method was to fly the test model given a certain RA like a kite in the flow. It depends on the value of the RA whether the parafoil can fly or not.

The behavior of the parafoil was obtained by a video camera. In addition, the dynamic pressure was changed in

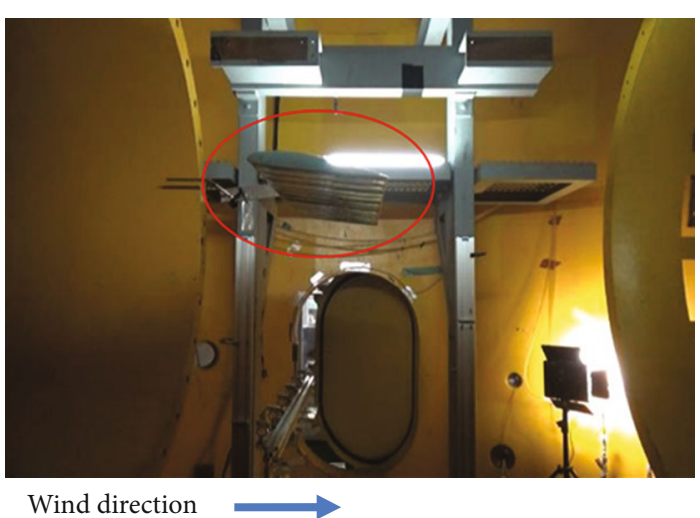

FIGURE 13: The picture of test model flying in the wind tunnel at a dynamic pressure of $60 \mathrm{~Pa}$ and RA of -4 degrees. 


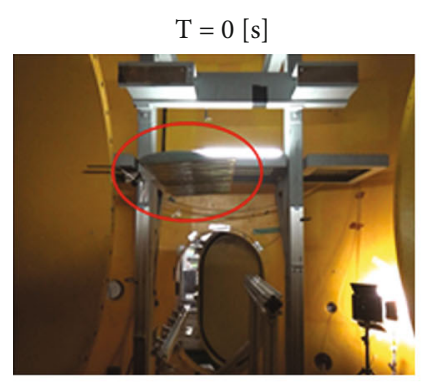

$\mathrm{T}=0.10[\mathrm{~s}]$

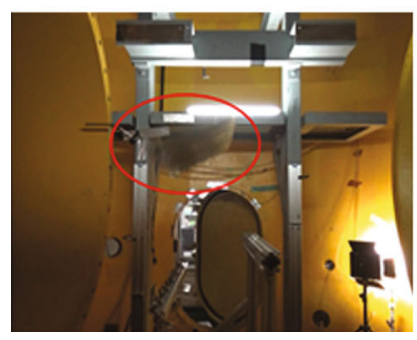

Wind direction
$\mathrm{T}=0.03[\mathrm{~s}]$

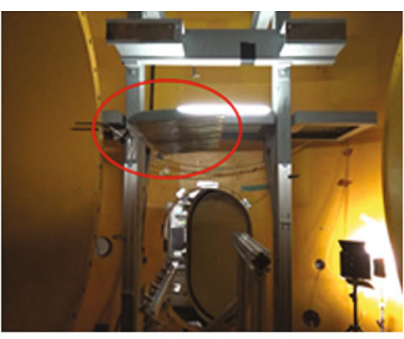

$\mathrm{T}=0.13[\mathrm{~s}]$

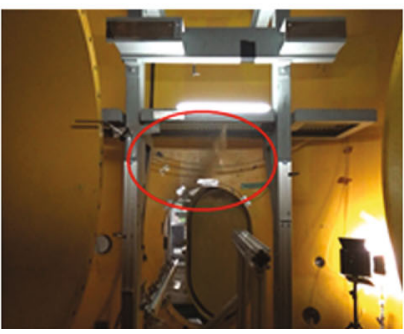

$\mathrm{T}=0.07[\mathrm{~s}]$

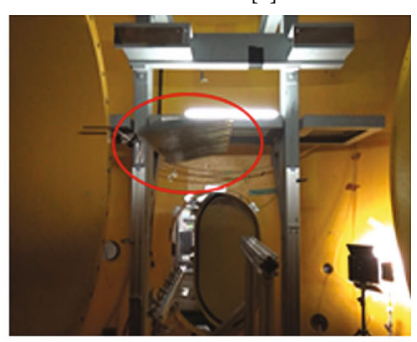

$\mathrm{T}=0.17[\mathrm{~s}]$

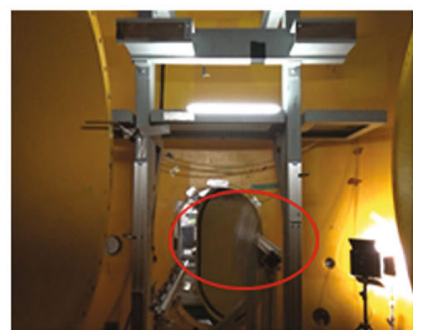

FIGURE 14: The time series pictures of test model collapsing to the front at RA of -9 degrees.

$\mathrm{T}=0[\mathrm{~s}]$

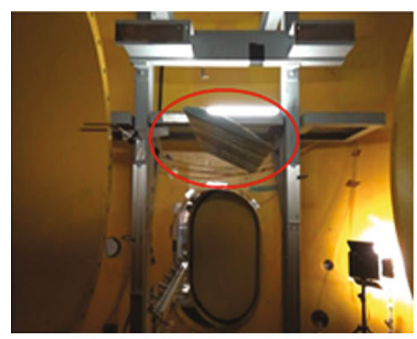

$\mathrm{T}=0.2[\mathrm{~s}]$

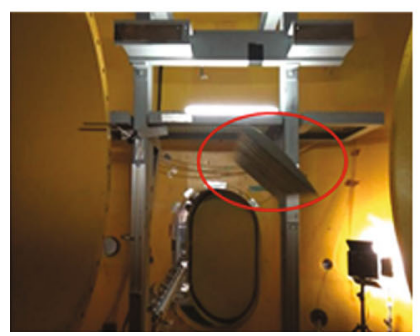

Wind direction
$\mathrm{T}=0.07[\mathrm{~s}]$

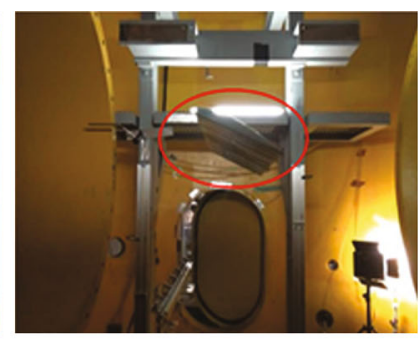

$\mathrm{T}=0.27[\mathrm{~s}]$

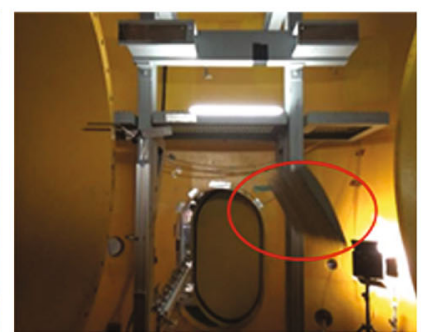

$\mathrm{T}=0.13[\mathrm{~s}]$

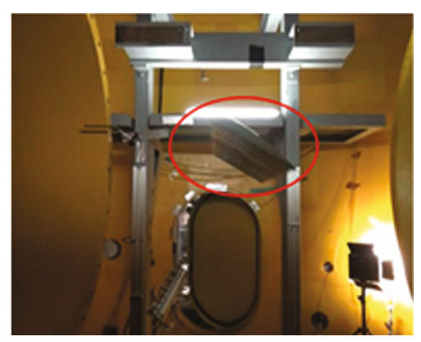

$\mathrm{T}=0.33[\mathrm{~s}]$

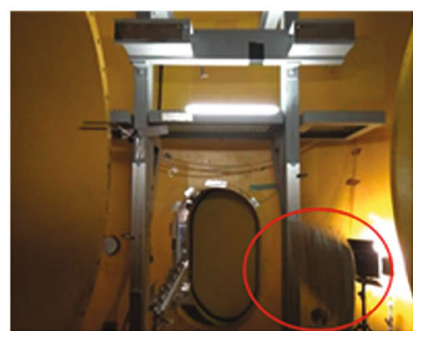

FIGURE 15: The time series pictures of test model falling down to the back at RA of 3 degrees.

order to investigate its effect on the flight attitude in the case that the test model is able to fly stably in the wind tunnel.

In the stable flight condition, the angle of attack of the parafoil in the trim attitude was obtained. As shown in Figure 11, a three-axis acceleration sensor-logger (sensor-logger: ninjascan-light) was mounted inside the parafoil to measure the angle of attack. The angle of the direction of gravity against sensor's attitude can be measured by this three-axis accelerometers. Assuming that the airflow direction was horizontal, the angle of attack of the parafoil was estimated from the angle between the sensor axis and the direction of gravity. The sampling rate was $100 \mathrm{~Hz}$. The angle of attack was calculated from the average of acceleration for 3 seconds. The uncertainty of the measurement results was evaluated using 95\% coverage based on the guidelines of the American Society of Mechanical Engineers. Table 3 shows the test parameters for this test. The RA was ranged from 4 to -9 degrees. The range of dynamic pressure was given from $60 \mathrm{~Pa}\left(\mathrm{Re}=2 \times 10^{5}\right)$ to $150 \mathrm{~Pa}$ $\left(\operatorname{Re}=3.2 \times 10^{5}\right)$. The turbulence intensity of the wind tunnel is $1 \%$ or less [14].

4.2. Result of Wind Tunnel Test. Figure 13 shows the parafoil during a trim flight in the wind tunnel at the dynamic pressure of $60 \mathrm{~Pa}$ and RA of -4 degrees. In this picture, the wind flows from left to right in the figure. The trim flight of 


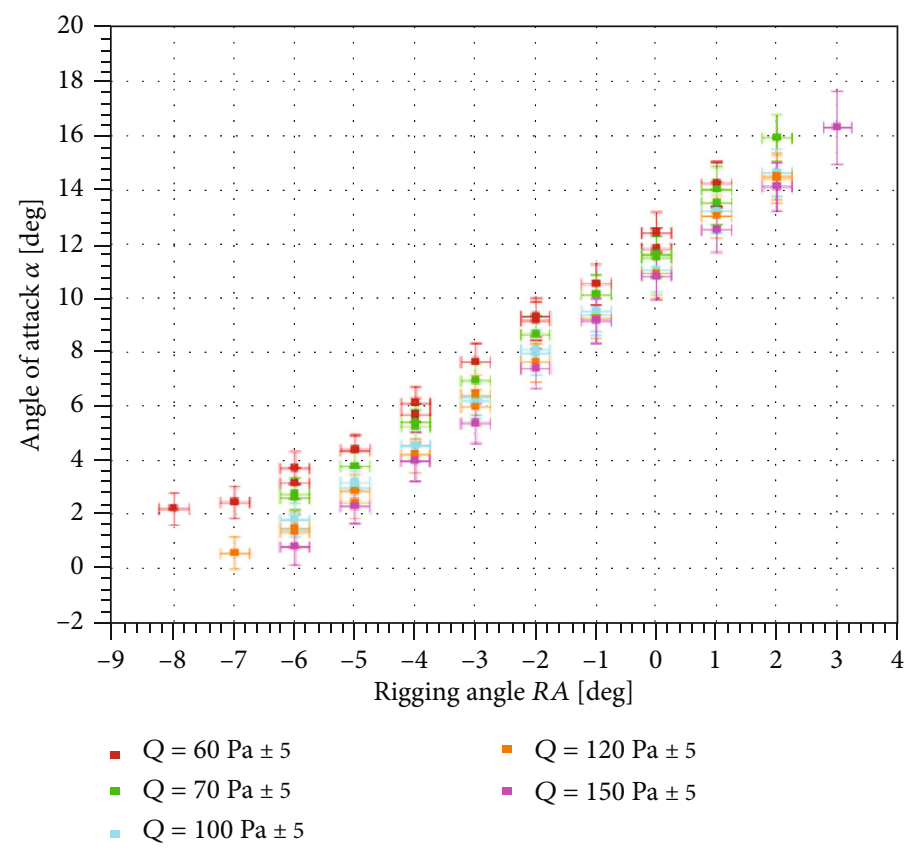

Figure 16: Relationship between RA and angle of attack in the stable flight in the wind tunnel tests.

the parafoil-type vehicle can be reproduced in the wind tunnel test.

Next, test cases where the RA of the test model is out of the allowable range for trim flight are described. Figure 14 shows the times series behavior of the parafoil at 0.03 -second intervals when the RA is smaller than stable flight RA ( $\mathrm{RA}=-9$ degrees.), and Figure 15 shows the time series behavior of the parafoil at 0.07 -second intervals when the $\mathrm{RA}$ is larger than the stable flight $\mathrm{RA}$ ( $\mathrm{RA}=3$ degrees). Note that the imaging in Figure 15 was conducted during flow acceleration to dynamic pressure of $60 \mathrm{~Pa}$ after the wind tunnel starting, and in Figure 15, the imaging was conducted during flow deceleration from the dynamic pressure of 150 to $120 \mathrm{~Pa}$. The reason why the image was taken during acceleration/deceleration is that the wind speed that transits from a stable flight state to an unstable state is accelerating or decelerating. The wind tunnel test model cannot fly even at unstable wind speeds condition. However, under unstable wind speed conditions, the test model does not maintain a stable state, and the unstable behavior of the parafoil cannot be captured unless it is supported by human hands. Therefore, in order to explain the motion behavior during unstable flight, it was taken during acceleration/deceleration.

When the RA was smaller than the stable flight RA, the parafoil collapsed to the front as shown in Figure 14. This collapse behavior is consistent with the prediction of the stability analysis. Next, the case where RA is large is described. As shown in Figure 15, the parafoil fell down to the back because of its pitch-up motion.

Table 6 summarizes success or failure of trim flight when the RA and the dynamic pressure are changed. From the wind tunnel test, the trim flight was achieved with the RA ranging from -8 to 1 degrees at $60 \mathrm{~Pa}$ dynamic pressure, and from -6 to 3 degrees at $150 \mathrm{~Pa}$ dynamic pressure. According to this result, even if the generated aerodynamic force was changed, the width of the stable flight RA did not change significantly, and only its range shifted at the wind tunnel test.

Next, the measurement results of the angle of attack of the parafoil in the stable flight are shown. Figure 16 shows the measurement results about the relation of the RA and the angle of attack at various dynamic pressures. The horizontal axis shows the RA, and the vertical axis shows the angle of attack of the parafoil. The measurement results in the wind tunnel test are shown in Tables 7-11. From this result, it can be seen that the trim flight angle of attack increases with the increase of RA. The maximum angle of attack was 16.1 degrees at the all test conditions. The maximum angle of attack was observed in the case that the RA is 3 degrees and a dynamic pressure is $150 \mathrm{~Pa}$. The minimum angle of attack was 0.5 degrees at the all test conditions. The minimum angle of attack was observed in the case that the $\mathrm{RA}$ is 7 degrees and a dynamic pressure is $120 \mathrm{~Pa}$. The angle of attack almost constantly increases respect to the RA regardless of the dynamic pressure. The tendency of the minimum value of the RA at the dynamic pressure of $60 \mathrm{~Pa}$ is different from the tendency of $120 \mathrm{~Pa}$, and the inclination of the angle of attack with respect to RA is more gentle. This is because, under the condition that the dynamic pressure is small (that means the lift generation is small), the moment around the fixed point of suspension lines caused by the gravity becomes relatively larger against the aerodynamic moment. When the parafoil flies at the same angle of attack in different dynamic pressure environments, the RA needs to be set higher as the dynamic pressure increases.

\section{Validity of Stability Analysis}

The effects of the RA on the attitude stability of the parafoil were compared between the stability analysis and the wind tunnel experiment, and the validity of the analysis was 
TABle 5: Coordinates of Clark Y airfoil.

\begin{tabular}{|c|c|c|c|c|c|c|c|}
\hline \multicolumn{4}{|c|}{ Upside of airfoil } & \multicolumn{4}{|c|}{ Downside of airfoil } \\
\hline $\mathrm{X} \mathrm{mm}$ & $\mathrm{Y} \mathrm{mm}$ & $\mathrm{X} \mathrm{mm}$ & Y mm & $\mathrm{X} \mathrm{mm}$ & $\mathrm{Y} \mathrm{mm}$ & $\mathrm{X} \mathrm{mm}$ & Y mm \\
\hline$\overline{0}$ & 0 & 138 & 26.59281 & 0 & 0 & 138 & -6.13059 \\
\hline 0.15 & 0.7017 & 144 & 26.20716 & 0.15 & -1.401 & 144 & -5.90958 \\
\hline 0.3 & 1.11813 & 150 & 25.76316 & 0.3 & -1.78254 & 150 & -5.68857 \\
\hline 0.6 & 1.74075 & 156 & 25.26435 & 0.6 & -2.34339 & 156 & -5.46786 \\
\hline 1.2 & 2.67714 & 162 & 24.71136 & 1.2 & -3.15378 & 162 & -5.24742 \\
\hline 2.4 & 4.1205 & 168 & 24.1044 & 2.4 & -4.28586 & 168 & -5.02716 \\
\hline 3.6 & 5.35743 & 174 & 23.44353 & 3.6 & -5.09199 & 174 & -4.80696 \\
\hline 6 & 7.61205 & 180 & 22.72899 & 6 & -6.08169 & 180 & -4.58679 \\
\hline 9 & 9.90645 & 186 & 21.96165 & 9 & -6.78168 & 186 & -4.36653 \\
\hline 12 & 11.73849 & 192 & 21.14466 & 12 & -7.35633 & 192 & -4.14621 \\
\hline 15 & 13.28259 & 198 & 20.28138 & 15 & -7.81356 & 198 & -3.92586 \\
\hline 18 & 14.62713 & 204 & 19.37529 & 18 & -8.13831 & 204 & -3.70545 \\
\hline 24 & 16.92924 & 210 & 18.42987 & 24 & -8.53785 & 210 & -3.48507 \\
\hline 30 & 18.89943 & 216 & 17.44797 & 30 & -8.81358 & 216 & -3.26469 \\
\hline 36 & 20.58612 & 222 & 16.43025 & 36 & -8.98899 & 222 & -3.04434 \\
\hline 42 & 22.0308 & 228 & 15.37695 & 42 & -9.07212 & 228 & -2.82399 \\
\hline 48 & 23.27121 & 234 & 14.28843 & 48 & -9.07638 & 234 & -2.60364 \\
\hline 54 & 24.32061 & 240 & 13.16508 & 54 & -9.0147 & 240 & -2.38329 \\
\hline 60 & 25.17606 & 246 & 12.00735 & 60 & -8.89968 & 246 & -2.16294 \\
\hline 66 & 25.84299 & 252 & 10.81608 & 66 & -8.74335 & 252 & -1.94259 \\
\hline 72 & 26.34924 & 258 & 9.5922 & 72 & -8.55543 & 258 & -1.72224 \\
\hline 78 & 26.7252 & 264 & 8.33673 & 78 & -8.34492 & 264 & -1.50189 \\
\hline 84 & 27.00048 & 270 & 7.05075 & 84 & -8.12088 & 270 & -1.28154 \\
\hline 90 & 27.20412 & 276 & 5.73468 & 90 & -7.89237 & 276 & -1.06119 \\
\hline 96 & 27.35571 & 282 & 4.38717 & 96 & -7.66695 & 282 & -0.84084 \\
\hline 102 & 27.45237 & 288 & 3.00696 & 102 & -7.44528 & 288 & -0.62049 \\
\hline 108 & 27.48798 & 291 & 2.30604 & 108 & -7.2261 & 291 & -0.51033 \\
\hline 114 & 27.45636 & 294 & 1.60005 & 114 & -7.00818 & 294 & -0.40017 \\
\hline 120 & 27.35136 & 297 & 0.8907 & 120 & -6.79023 & 297 & -0.28998 \\
\hline 126 & 27.16971 & 300 & 0.17979 & 126 & -6.57126 & 300 & -0.17979 \\
\hline 132 & 26.91525 & - & - & 132 & -6.35124 & - & - \\
\hline
\end{tabular}

TABLE 6: Summary of the wind tunnel test results; stable flight is $\bigcirc$ and unstable flight is $\times$.

\begin{tabular}{|c|c|c|c|c|c|c|c|c|c|c|c|c|c|c|}
\hline Dynamic & & & & & Rigg & ging & an & gle | & deg & & & & & \\
\hline pressure $[\mathrm{Pa}]$ & -9 & -8 & -7 & -6 & -5 & -4 & -3 & -2 & -1 & 0 & 1 & 2 & 3 & 4 \\
\hline 60 & $x$ & $\mathrm{O}$ & O & O & $\mathrm{O}$ & $\mathrm{O}$ & O & $\mathrm{O}$ & O & O & O & $x$ & $x$ & $x$ \\
\hline 70 & $x$ & O & ○ & O & $\mathrm{O}$ & O & O & O & O & O & O & O & $x$ & $x$ \\
\hline 100 & $x$ & $x$ & O & 0 & 0 & O & O & $\mathrm{O}$ & O & O & O & O & $x$ & $x$ \\
\hline 120 & $x$ & $x$ & O & 0 & 0 & O & O & $\mathrm{O}$ & O & $\mathrm{O}$ & O & O & $x$ & $x$ \\
\hline 150 & $x$ & $x$ & $x$ & 0 & $\mathrm{O}$ & O & O & $\mathrm{O}$ & O & $\mathrm{O}$ & $\mathrm{O}$ & O & O & $x$ \\
\hline
\end{tabular}

verified. First, the effect of the RA change on the attitude behavior of the parafoil is compared. In the stability analysis, it was found that the RA has a certain range for the stable flight. At this time, the parafoil stabilizes around a certain trim angle during the stable flight. In the wind tunnel test as well, it was also found that there was a certain range of the RA for the stable flight.

Next, the attitude behavior at smaller RA than the stable flight RA is described. In the analysis, it was predicted that the tension of the front suspension line becomes negative (that means the compression load applies to the line), and the parafoil collapses to the front. Similarly, in the wind tunnel test, the front suspension line was slackened and collapsed to the front. In both the analysis and the wind tunnel test, the same parafoil behavior was observed.

The behavior at larger RA than the stable flight RA is discussed. In the analysis, it was expected that the parafoil would fall down backward without having a trim flight point. In the wind tunnel test, it showed the behavior of falling down backward as expected in the analysis.

Next, the analysis and experimental results of effect of the RA on parafoil attitude under different dynamic pressure environments are compared. In the stability analysis 
TABLE 7: Wind tunnel test result of $60 \mathrm{~Pa}$ wind condition.

\begin{tabular}{|c|c|c|c|c|c|c|}
\hline $\begin{array}{l}\text { Data } \\
\text { number }\end{array}$ & $\begin{array}{l}\text { Rigging angle } \\
R A \text { [deg] }\end{array}$ & $\begin{array}{c}\text { Uncertainty } \\
\text { of } R A\end{array}$ & $\begin{array}{l}\text { Angle of attack } \\
\alpha[\mathrm{deg}]\end{array}$ & $\begin{array}{c}\text { Uncertainty } \\
\text { of } \alpha\end{array}$ & $\begin{array}{c}\text { Angle of attitude } \\
\theta[\mathrm{deg}]\end{array}$ & $\begin{array}{l}\text { Uncertainty } \\
\text { of } \theta\end{array}$ \\
\hline 1 & -9.0 & 0.25 & -0.471 & 0.581 & -9.471 & 0.631 \\
\hline 2 & -8.0 & 0.25 & 2.147 & 0.587 & -5.853 & 0.637 \\
\hline 3 & -7.0 & 0.24 & 2.380 & 0.583 & -4.620 & 0.632 \\
\hline 4 & -6.0 & 0.24 & 3.651 & 0.596 & -2.349 & 0.644 \\
\hline 5 & -6.0 & 0.24 & 3.068 & 0.585 & -2.932 & 0.634 \\
\hline 6 & -5.0 & 0.24 & 4.292 & 0.604 & -0.708 & 0.651 \\
\hline 7 & -5.0 & 0.24 & 4.360 & 0.616 & -0.640 & 0.663 \\
\hline 8 & -4.0 & 0.24 & 6.075 & 0.640 & 2.075 & 0.685 \\
\hline 9 & -4.0 & 0.24 & 5.650 & 0.628 & 1.650 & 0.674 \\
\hline 10 & -3.0 & 0.24 & 7.613 & 0.696 & 4.613 & 0.737 \\
\hline 11 & -2.0 & 0.24 & 9.140 & 0.693 & 7.140 & 0.735 \\
\hline 12 & -2.0 & 0.24 & 9.280 & 0.709 & 7.280 & 0.749 \\
\hline 13 & -1.0 & 0.24 & 10.50 & 0.761 & 9.500 & 0.799 \\
\hline 14 & 0.0 & 0.24 & 11.80 & 0.767 & 11.80 & 0.804 \\
\hline 15 & 0.0 & 0.24 & 12.40 & 0.782 & 12.40 & 0.819 \\
\hline 16 & 1.0 & 0.24 & 14.23 & 0.838 & 15.23 & 0.872 \\
\hline 17 & 1.0 & 0.24 & 14.24 & 0.816 & 15.24 & 0.851 \\
\hline
\end{tabular}

TABLE 8: Wind tunnel test result of $70 \mathrm{~Pa}$ wind condition.

\begin{tabular}{|c|c|c|c|c|c|c|}
\hline $\begin{array}{l}\text { Data } \\
\text { number }\end{array}$ & $\begin{array}{c}\text { Rigging angle } \\
R A \text { [deg] }\end{array}$ & $\begin{array}{c}\text { Uncertainty } \\
\text { of } R A\end{array}$ & $\begin{array}{l}\text { Angle of attack } \\
\quad \alpha[\mathrm{deg}]\end{array}$ & $\begin{array}{c}\text { Uncertainty } \\
\text { of } \alpha\end{array}$ & $\begin{array}{c}\text { Angle of attitude } \\
\theta[\mathrm{deg}]\end{array}$ & $\begin{array}{l}\text { Uncertainty } \\
\text { of } \theta\end{array}$ \\
\hline 1 & -8.0 & 0.25 & 1.999 & 0.583 & -6.001 & 0.632 \\
\hline 2 & -6.0 & 0.24 & 2.518 & 0.589 & -3.482 & 0.638 \\
\hline 3 & -6.0 & 0.24 & 2.694 & 0.597 & -3.306 & 0.645 \\
\hline 4 & -5.0 & 0.24 & 3.715 & 0.602 & -1.285 & 0.649 \\
\hline 5 & -4.0 & 0.24 & 5.399 & 0.639 & 1.399 & 0.684 \\
\hline 6 & -4.0 & 0.24 & 5.237 & 0.631 & 1.237 & 0.676 \\
\hline 7 & -3.0 & 0.24 & 6.909 & 0.646 & 3.909 & 0.690 \\
\hline 8 & -2.0 & 0.24 & 8.630 & 0.697 & 6.630 & 0.738 \\
\hline 9 & -1.0 & 0.24 & 10.10 & 0.743 & 9.100 & 0.782 \\
\hline 10 & 0.0 & 0.24 & 11.60 & 0.767 & 11.60 & 0.804 \\
\hline 11 & 0.0 & 0.24 & 11.50 & 0.773 & 11.50 & 0.810 \\
\hline 12 & 1.0 & 0.24 & 13.96 & 0.829 & 14.96 & 0.864 \\
\hline 13 & 1.0 & 0.24 & 13.51 & 0.808 & 14.51 & 0.844 \\
\hline 14 & 2.0 & 0.24 & 15.89 & 0.866 & 17.89 & 0.900 \\
\hline
\end{tabular}

described in the previous section, the analysis was performed by giving different dynamic pressure conditions. Additionally, the results in the case that the dynamic pressure is varied as the same as the wind tunnel experiment is introduced in this section. The applied dynamic pressure conditions were $60 \mathrm{~Pa}$ to $150 \mathrm{~Pa}$ as in the experiment. The analysis results are shown in Figure 17 together with the experimental results. The horizontal axis shows the RA and the vertical axis shows the angle of attitude of the parafoil. The plots are the experimental results, and the lines are the analytical results. In the graph, the solid lines are the analytical results of the stable flight, and the dashed lines are those of unstable behavior. The analysis results at all dynamic pressure cases show that the angle of attitude tends to increase with increasing the RA when the RA is larger than -5 degrees. However, when the RA is smaller than -7 degrees, the tendency is different depending on the dynamic pressure. In the case of the lower dynamic pressure than $70 \mathrm{~Pa}$, the angle of attitude does not decrease and conversely gently increases as the decrease of the RA. On the other hand, in the case of higher dynamic pressure than $70 \mathrm{~Pa}$, the angle of attitude sharply decreases with the decrease of the RA. And, according to these results, the trim angle of the 
TABLE 9: Wind tunnel test result of $100 \mathrm{~Pa}$ wind condition.

\begin{tabular}{|c|c|c|c|c|c|c|}
\hline $\begin{array}{l}\text { Data } \\
\text { number }\end{array}$ & $\begin{array}{l}\text { Rigging angle } \\
R A \text { [deg] }\end{array}$ & $\begin{array}{l}\text { Uncertainty } \\
\text { of } R A\end{array}$ & $\begin{array}{c}\text { Angle of attack } \\
\alpha[\mathrm{deg}]\end{array}$ & $\begin{array}{l}\text { Uncertainty } \\
\text { of } \alpha\end{array}$ & $\begin{array}{c}\text { Angle of attitude } \\
\theta[\mathrm{deg}]\end{array}$ & $\begin{array}{c}\text { Uncertainty } \\
\text { of } \theta\end{array}$ \\
\hline 1 & -6.0 & 0.24 & 1.742 & 0.599 & -4.258 & 0.647 \\
\hline 2 & -6.0 & 0.24 & 1.372 & 0.612 & -4.628 & 0.659 \\
\hline 3 & -5.0 & 0.24 & 3.136 & 0.605 & -1.864 & 0.652 \\
\hline 4 & -5.0 & 0.24 & 2.898 & 0.601 & -2.102 & 0.649 \\
\hline 5 & -4.0 & 0.24 & 4.534 & 0.621 & 0.534 & 0.667 \\
\hline 6 & -4.0 & 0.24 & 4.509 & 0.636 & 0.509 & 0.681 \\
\hline 7 & -3.0 & 0.24 & 6.157 & 0.660 & 3.157 & 0.703 \\
\hline 8 & -3.0 & 0.24 & 6.320 & 0.681 & 3.320 & 0.723 \\
\hline 9 & -2.0 & 0.24 & 8.100 & 0.723 & 6.100 & 0.763 \\
\hline 10 & -2.0 & 0.24 & 7.920 & 0.777 & 5.920 & 0.814 \\
\hline 11 & -1.0 & 0.24 & 9.500 & 0.746 & 8.500 & 0.784 \\
\hline 12 & -1.0 & 0.24 & 9.350 & 0.768 & 8.350 & 0.805 \\
\hline 13 & 0.0 & 0.24 & 11.00 & 0.802 & 11.00 & 0.838 \\
\hline 14 & 1.0 & 0.24 & 13.03 & 0.801 & 14.03 & 0.837 \\
\hline 15 & 1.0 & 0.24 & 13.22 & 0.815 & 14.22 & 0.850 \\
\hline 16 & 2.0 & 0.24 & 14.63 & 0.853 & 16.63 & 0.887 \\
\hline
\end{tabular}

TABLE 10: Wind tunnel test result of $120 \mathrm{~Pa}$ wind condition.

\begin{tabular}{|c|c|c|c|c|c|c|}
\hline $\begin{array}{l}\text { Data } \\
\text { number }\end{array}$ & $\begin{array}{c}\text { Rigging angle } \\
R A[\mathrm{deg}]\end{array}$ & $\begin{array}{c}\text { Uncertainty } \\
\text { of } R A\end{array}$ & $\begin{array}{c}\text { Angle of attack } \\
\alpha[\mathrm{deg}]\end{array}$ & $\begin{array}{c}\text { Uncertainty } \\
\text { of } \alpha\end{array}$ & $\begin{array}{c}\text { Angle of attitude } \\
\theta[\mathrm{deg}]\end{array}$ & $\begin{array}{c}\text { Uncertainty } \\
\text { of } \theta \\
\end{array}$ \\
\hline 1 & -7.0 & 0.24 & 0.525 & 0.600 & -6.475 & 0.648 \\
\hline 2 & -6.0 & 0.24 & 1.298 & 0.614 & -4.702 & 0.661 \\
\hline 3 & -6.0 & 0.24 & 1.451 & 0.637 & -4.549 & 0.683 \\
\hline 4 & -5.0 & 0.24 & 2.404 & 0.609 & -2.596 & 0.656 \\
\hline 5 & -5.0 & 0.24 & 2.766 & 0.619 & -2.234 & 0.666 \\
\hline 6 & -4.0 & 0.24 & 4.142 & 0.644 & 0.142 & 0.688 \\
\hline 7 & -3.0 & 0.24 & 6.416 & 0.742 & 3.416 & 0.780 \\
\hline 8 & -3.0 & 0.24 & 5.951 & 0.669 & 2.951 & 0.712 \\
\hline 9 & -2.0 & 0.24 & 7.610 & 0.728 & 5.610 & 0.767 \\
\hline 10 & -1.0 & 0.24 & 9.210 & 0.751 & 8.210 & 0.789 \\
\hline 11 & 0.0 & 0.24 & 10.80 & 0.836 & 10.80 & 0.870 \\
\hline 12 & 0.0 & 0.24 & 10.90 & 0.821 & 10.90 & 0.856 \\
\hline 13 & 1.0 & 0.24 & 13.05 & 0.802 & 14.05 & 0.838 \\
\hline 14 & 2.0 & 0.24 & 14.47 & 0.869 & 16.47 & 0.902 \\
\hline 15 & 2.0 & 0.24 & 14.44 & 0.874 & 16.44 & 0.907 \\
\hline
\end{tabular}

attitude of the parafoil-type vehicle with certain fixed RA decreases when the dynamic pressure increases.

From comparison with the experimental results, it can be found that although there are quantitative discrepancies, the qualitative tendency of the analysis is in agreement with that of the experiment; the trim angle of attitude increases with the increase of the RA at high RA range, but its tendency changes depending on the dynamic pressure at low RA range, and in addition, the trim angle of attitude decreases as the dynamic pressure increases. However, the sharp decrease in trim angle of attitude at low RA range in high dynamic pressure was not observed in the experiment.

This is because the step of the RA in the experiment was only 1 degree, so the resolution was not enough. The quantitative discrepancies are considered to be due to the accuracy of the aerodynamic characteristic model of the airfoil in the analysis. However, it is considered that there is no significant effect in verifying the validity of the dynamics model for the analysis. From these results, the stability analysis proposed in this study can quantitatively predict parafoil behavior. 
TABLE 11: Wind tunnel test result of $150 \mathrm{~Pa}$ wind condition.

\begin{tabular}{|c|c|c|c|c|c|c|}
\hline $\begin{array}{l}\text { Data } \\
\text { number }\end{array}$ & $\begin{array}{c}\text { Rigging angle } R A \\
\text { [deg] }\end{array}$ & $\begin{array}{c}\text { Uncertainty of } \\
R A\end{array}$ & $\begin{array}{c}\text { Angle of attack } \alpha \\
{[\mathrm{deg}]}\end{array}$ & $\begin{array}{c}\text { Uncertainty of } \\
\alpha\end{array}$ & $\begin{array}{c}\text { Angle of attitude } \theta \\
\text { [deg] }\end{array}$ & $\begin{array}{c}\text { Uncertainty of } \\
\theta\end{array}$ \\
\hline 1 & -6.0 & 0.24 & 0.726 & 0.646 & -5.274 & 0.691 \\
\hline 2 & -5.0 & 0.24 & 2.227 & 0.627 & -2.773 & 0.672 \\
\hline 3 & -4.0 & 0.24 & 3.924 & 0.748 & -0.076 & 0.786 \\
\hline 4 & -3.0 & 0.24 & 5.344 & 0.745 & 2.344 & 0.784 \\
\hline 5 & -2.0 & 0.24 & 7.390 & 0.744 & 5.390 & 0.782 \\
\hline 6 & -1.0 & 0.24 & 9.140 & 0.832 & 8.140 & 0.866 \\
\hline 7 & 0.0 & 0.24 & 10.80 & 0.895 & 10.80 & 0.927 \\
\hline 8 & 1.0 & 0.24 & 12.48 & 0.808 & 13.48 & 0.843 \\
\hline 9 & 2.0 & 0.24 & 14.09 & 0.903 & 16.09 & 0.935 \\
\hline 10 & 3.0 & 0.24 & 16.35 & 1.367 & 19.35 & 1.388 \\
\hline
\end{tabular}

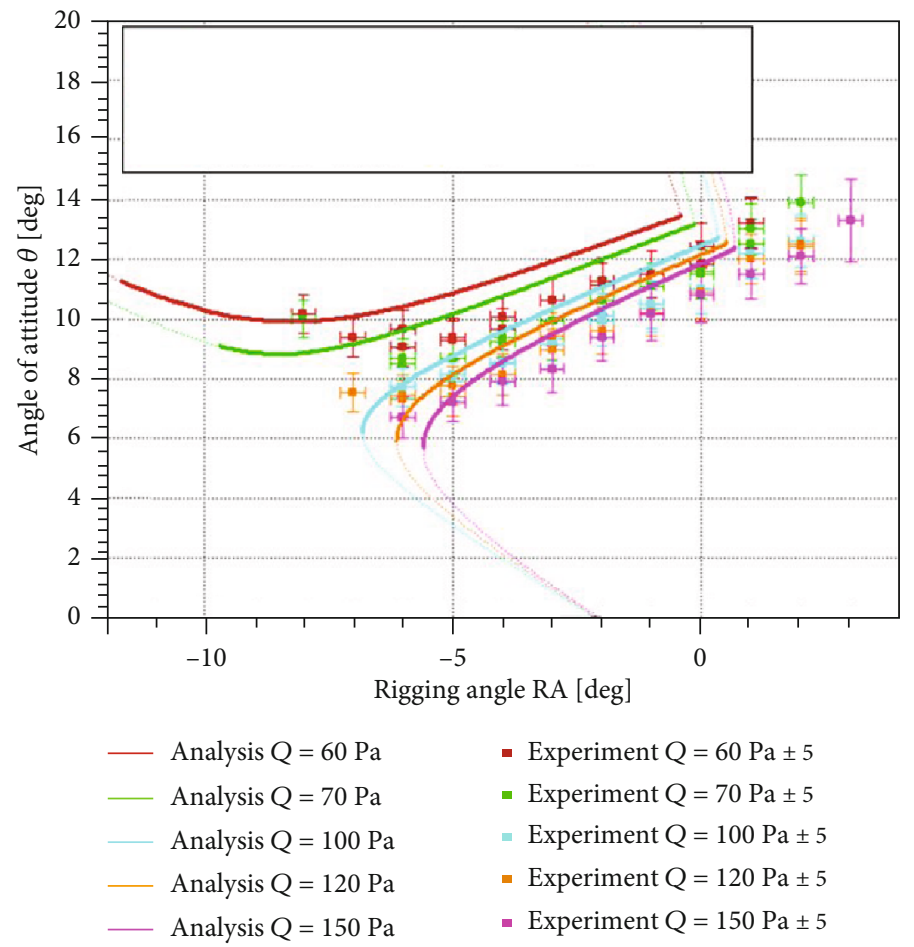

FIGURE 17: Analysis and experimental results of effect of RA on parafoil attitude under different dynamic pressure environments.

\section{Prediction in the Flight Condition}

The stability analysis and the wind tunnel tests showed that the flight angle of attack could be changed depending on the RA. In addition, it was confirmed that the flight angle of attack was affected also by the dynamic pressure. For practical use, the dynamic pressure is determined according to the vehicle mass and the area of the parafoil. And, in actual flight, because the longitudinal direction motion of the vehicle is rotated around the center of gravity, the gravity force applied to the parafoil is ignored from the viewpoint of the longitudinal direction motion [4]. At this time, when the payload weight is sufficiently large with respect to the parafoil, the center of gravity becomes close to the payload, and the center of longitudinal direction motion can be approxi- mated to the payload. The equation for stability analysis in longitudinal direction in the actual flight condition is derived as following, from equations (1) and ((2a), (2b)) by omitting the gravity term and non-dimensionalizing.

$$
\begin{aligned}
C_{N}(\alpha, \theta)(\mathrm{CG}-x) \cos \mathrm{RA}+C_{A}(\alpha, \theta)\left(\frac{\mathrm{MLL}}{c}+(\mathrm{CG}-x) \sin \mathrm{RA}\right) \\
+C_{M}(\alpha)=\frac{m \mathrm{MLL}^{2}}{c Q S} \frac{d^{2} \theta}{d t^{2}} \\
C_{N}=C_{L} \cos \theta+C_{D} \sin \theta \\
C_{A}=-C_{L} \sin \theta+C_{D} \cos \theta
\end{aligned}
$$




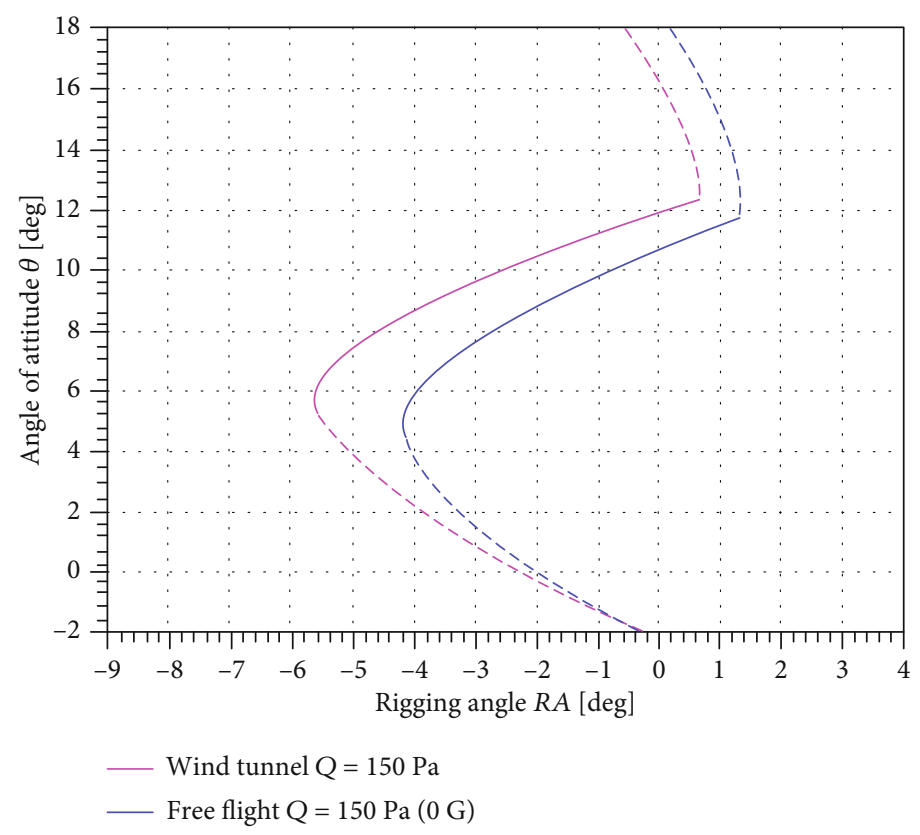

FIgURE 18: The analysis results of RA and parafoil attitude under high dynamic pressure and weightless conditions.

This indicates that the dynamic pressure was also irrelevant to the attitude stability of the vehicle. Furthermore, when a stability analysis was performed under the same design parameters and other conditions in this equation, the results were shown in Figure 18. From Figure 18, it can be seen that under actual flight conditions, the RA range in the wind tunnel test is shifted to the positive side. The reason for this was that the gravity acting on the parafoil in the wind tunnel test condition generated a moment that tilted toward the trailing edge.

If the preflight test is carried out by a wind tunnel test, the RA must be not set to lower limit in allowable range obtained in the wind tunnel test. If the RA is set to the lower limit for stable flight in the wind tunnel, the parafoil is expected to collapse during actual flight. This should be avoided because the lower limit value shifts to the upper side because the influence of gravity is lost, and it becomes impossible to fly.

In addition, attitude of parafoil vehicle in flight condition is expected to be shifted in pitch-down direction, because the gravity effect is omitted, and it is considered that the trim angle of attitude requires an enough margin to allow its shift. Therefore, it is important to avoid the lower limit of RA obtained by wind tunnel test in order to prevent parafoil collapse.

\section{Conclusions}

In this study, the tendency of attitude stability of parafoiltype vehicle was clarified by the two-dimensional attitude stability analysis and the wind tunnel tests, especially focusing on the rigging angle (RA) which is an important design parameter for the stability. As a result, it was found that the flight angle of attitude of the parafoil changes depending on the dynamic pressure or the RA even if other design parameters fixed. At this time, there was an allowable range that can be set in the RA for the stable flight. And the parafoil is not stable out of this range.
It was found that the parafoil fell toward the trailing edge if the RA is outside the upper limit of the RA allowable range. Outside the lower limit, the parafoil collapsed in the direction of the leading edge. When the RA is set within the allowable range of the RA, the flight angle of attitude is determined depending on the value of the RA. Following this, the flight angle of attack and the aerodynamic characteristics are determined. Both the analysis and the experiment showed that when the RA is large, the flight angle of attitude also becomes large in the pitch-up direction. The increase of dynamic pressure has the effect of changing the flight angle of attitude in the pitch-down direction in situations where the payload is fixed, such as wind tunnel tests. However, it was found that the flight angle of attitude was not affected by the dynamic pressure in the situation where gravity was not added to the parafoil, such as actual flight. And, the allowable range for stable flight in actual flight condition shifts to the larger RA, comparing with the wind tunnel condition. Therefore, it was found that the lower limit of the RA in the wind tunnel test was likely to cause the parafoil to collapse in the pitch-down direction in an actual flight environment. Therefore, to keep the stable flight of the parafoil, it is necessary to avoid near the lower limit of the RA which is observe in the wind tunnel tests. In addition, when determining the aerodynamic characteristics of a parafoil-type vehicle during flight, it is important to determine the optimal RA in addition to the parafoil area and the wing shape.

Finally, the effect of RA on the attitude stability of parafoil revealed in this study is considered to have the same tendency in inflatable parafoil. This is because the aerodynamic coefficient of the inflatable parafoil has a characteristic that depends on the angle of attack, similar to the aerodynamic characteristic of the virtual parafoil given in the stability analysis. 


\section{Abbreviations}

$\alpha: \quad$ Angle of attack

$\alpha_{0} *$ : $\quad$ Zero lift angle

$\alpha_{\text {lim }}: \quad$ Angle of stall

$C_{L, \alpha}$ : Lift curve slope

$C_{L 2, \alpha}: \quad$ Lift curve slope after the angle of stall

$C_{D \text { min }}$ : Minimum parasite drag coefficient

$e: \quad$ Airplane efficient

$C_{A}$ : Axial force coefficient

$C_{N}: \quad$ Nominal force coefficient

$C_{M}$ : Moment coefficient

A: $\quad$ Axial force for the vertical axis of analysis model

$N$ : $\quad$ Nominal force for the vertical axis of analysis model

L: $\quad$ Lift force due to aerodynamic force

$D$ : $\quad$ Drag force due to aerodynamic force

M: $\quad$ Pitching moment due to aerodynamic force

$M_{m g}$ : Pitching moment due to the gravity force

Q: $\quad$ Dynamic pressure

AR: Aspect ratio

$S$ : Wing area

c: $\quad$ Chord length

ac: $\quad$ Aerodynamic center

$m$ : $\quad$ Mass of parafoil

$\theta: \quad$ Angle of attitude

$\gamma: \quad$ Equivalent gliding angle

CG: Center of gravity

RA: $\quad$ Rigging angle

MLL: Mean line length

g: $\quad$ Gravitational acceleration

T: $\quad$ Tension of suspension lines

$\psi$ : $\quad$ Angle between suspension line and the vertical axis.

\section{Data Availability}

Data is available upon request.

\section{Conflicts of Interest}

The authors declare that they have no conflicts of interest.

\section{References}

[1] K. Yamada, K. Suzuki, D. Akita et al., Innovative Aerodynamic Techniques Using Inflatable Structure for Future Martian EDL Mission, APISAT, 2013.

[2] T. Moriyoshi, H. Kanemaru, H. Nagano et al., "Study on New Generation Flying Mars Exploration Using Membrane Aeroshell and Paraglider," in Proceedings of 61th Space Sciences and Technology Conference, JSASS-2017-4284, Nigata, Japan, 2017.

[3] J. Benton and O. Yakimenko, "On Development of Autonomous HAHO Parafoil System for Targeted Payload Return," in 22nd AIAA Aerodynamic Decelerator Systems Technology Conferences, Daytona Beach, FL, USA, 2013.

[4] O. Yakimenko, Precision Aerial Delivery Systems: Modeling, Dynamics, and Control, AIAA, 2015.

[5] J. S. Lingard, The Performance and Design of ram-air Gliding Parachutes, Procurement Executive, Ministry of Defense, 1981.
[6] J. Stein, R. Machin, and J. Muratore, "An Overview of the X-38 Prototype Crew Return Vehicle Development and Test Program," in 15th Aerodynamic Decelerator Systems Technology Conference, Toulouse, France, 1999.

[7] C. S. Iacomini and C. M. Madsen, "Investigation of large scale parafoil rigging angles: analytical and drop test results," in 15th Aerodynamic Decelerator Systems Technology Conference, Toulouse,France, 1999.

[8] M. Ward, A. Gavrilovski, and M. Costello, "Flight test results for glide slope control of parafoil canopies of various aspect ratios," in 21st AIAA Aerodynamic Decelerator Systems Technology Conference and Seminar, Dublin, Ireland, 2011.

[9] E. Willemsen, D. Rozendal, P. Hollestelle, and G. Elbertsen, "The FASTWing project: wind tunnel tests, realization and results," in 18th AIAA Aerodynamic Decelerator Systems Technology Conference and Seminar, Munich, Germany, 2005.

[10] T. Moriyoshi, H. Maekawa, K. Yamada, T. Abe, and H. Nishida, "Flight Stability Analysis for Parafoil-Type Vehicle," in Proceedings of 30th International Symposium on Space Technology and Science, Kobe, Japan, 2015.

[11] H. Ira, A. Abbott, and E. von Doenhoff, Theory of Wing Sections: Including a Summary of Airfoil Data, McGraw-Hill Book, 1949.

[12] A. Piccirillo, "The Clark Y Airfoil - a Historical Retrospective," in 2000 World Aviation Conference, AIAA, San Diego, CA, USA, 2000.

[13] Y. Clark2020, http://www.airfoiltools.com/airfoil/ details?airfoil=clarky-il.

[14] K. Ohshima, Y. Tokunaga, and Y. Ohshima, "APlanetary atmosphere wind tunnel," Journal of The Japan Society for Aeronautical and Space Science, vol. 31, pp. 215-219, 1983. 